S. Lally • C. Y. Tan • D. Owens - G. H. Tomkin

\title{
Messenger RNA levels of genes involved in dysregulation of postprandial lipoproteins in type 2 diabetes: the role of Niemann-Pick C1-like 1, ATP-binding cassette, transporters G5 and G8, and of microsomal triglyceride transfer protein
}

Received: 12 August 2005 / Accepted: 3 December 2005 / Published online: 4 March 2006

C) Springer-Verlag 2006

\begin{abstract}
Aims/hypothesis: The aim of the present study was to examine the relationship between chylomicron composition and expression of genes that regulate chylomicron production in the intestine. We examined expression of the following: (1) Niemann-Pick C1-like 1 (NPC1L1), which regulates cholesterol absorption; (2) ATP-binding cassette transporters G5 and G8 (ABCG5, ABCG8), which regulate cholesterol homeostasis through their ability to excrete enterocyte cholesterol back into the lumen of the intestine; and (3) microsomal triglyceride transfer protein (MTTP), which packages the chylomicron particle by assembling cholesterol, triglyceride, phospholipids and apolipoprotein B48. Subjects, materials and methods: Type 2 diabetic (26) and non-diabetic (21) patients were examined. Levels of NPC1L1, ABCG5 and $A B C G 8$ and MTTP mRNA were measured in duodenal biopsies by real-time PCR. Lipoproteins were isolated by sequential ultracentrifugation. Results: Diabetic patients had more NPC1L1 mRNA than the control subjects $(p<0.02)$. Expression of $A B C G 5$ and $A B C G 8$ mRNA was lower in the diabetic patients $(p<0.05)$ and MTTP expression was increased $(p<0.05)$. There was a positive correlation between NPLC1L1 and MTTP mRNA $(p<0.01)$ and a negative correlation between NPC1L1 and ABCG5 mRNA $(p<0.001)$. Diabetic patients on statin therapy had increased $A B C G 5$ and $A B C G 8$ mRNA compared to those not on statin $(p<0.02$ and $p<0.05)$ and less MTTP mRNA than those not on statin $(p<0.05)$. Conclusions/ interpretation: This study demonstrates that in type 2 diabetes there are important alterations to the expression of
\end{abstract}

S. Lally $\cdot$ C. Y. Tan $\cdot$ D. Owens $\cdot$ G. H. Tomkin Department of Diabetes and Endocrinology, Trinity College, Dublin, Ireland

G. H. Tomkin $(\bowtie)$

Diabetes Research Foundation,

Clontra, Quinns Road, Shankill,

Co Dublin, Ireland

e-mail: gerald.tomkin@tcd.ie

Tel.: +353-1-2390658

Fax: +353-1-2721395 intestinal genes that regulate cholesterol absorption and chylomicron synthesis. In diabetic patients statin therapy is associated with reduced MTTP expression and increased $A B C G 5$ and $A B C G 8$ mRNA. The study suggests new mechanisms to explain postprandial diabetic dyslipidaemia and the beneficial effect of statins.

Keywords ABCG5 - ABCG8 - Apo B48 - Apo B100 · Chylomicron composition - Microsomal triglyceride transfer protein - MTTP · Niemann Pick C1-like1 . Type 2 diabetes

Abbreviations ABCG5: ATP-binding cassette transporter G5 - ABCG8: ATP-binding cassette transporter G8 - Apo: apolipoprotein - AU: arbitrary units - GAPDH: glyceraldehyde-3-phosphate dehydrogenase - HMGCoA: 3-hydroxy-3-methylglutaryl coenzyme A - MTTP: microsomal triglyceride transfer protein $\cdot \mathrm{NPC} 1 \mathrm{~L} 1$ : Niemann-Pick C1-like 1

\section{Introduction}

Diabetes is responsible for a large increase in cardiovascular risk, which in many studies has not been reduced by improvement in blood sugar control. The postprandial period in diabetes is associated with considerable disturbance in fatty acid and triglyceride metabolism [1] and this may be an important factor in atherosclerosis development [2]. In particular the postprandial period in diabetes is associated with increased apolipoprotein (Apo) B48, the solubilising protein for transport of intestinal cholesterol and triglyceride in the blood stream [3, 4]. These Apo B48containing chylomicron particles may be particularly atherogenic $[5,6]$. Reduced clearance of these particles plays a part in the raised levels $[7,8]$, but we have also demonstrated increased cholesterol synthesis in the intestine in animal models of diabetes $[9,10]$ and human studies have suggested that the early postprandial rise in Apo B48 is probably due to increased chylomicron particle synthesis rather than delayed clearance $[3,11]$. 
Microsomal triglyceride transfer protein (MTTP) is responsible for the assembly of cholesterol, triglyceride and phospholipids together with one Apo B48 molecule to form the chylomicron particle in the intestine, and with one Apo B100 molecule to form VLDL in the liver [12, 13]. The cholesterol in the chylomicron particle may either be absorbed from the diet, absorbed from recycled biliary cholesterol or derived from de novo cholesterol synthesis in the intestine. It has been suggested that $25 \%$ of newly synthesised cholesterol is derived from the intestine. In animals with diabetes, cholesterol synthesis is increased as evidenced by the increase in 3-hydroxy-3-methylglutaryl coenzyme A (HMGCoA) reductase, the rate-limiting enzyme for cholesterol synthesis $[9,14]$.

The ATP binding cassette transporters G5 (ABCG5) and G8 (ABCG8) regulate cholesterol absorption from the intestine by their ability to work in tandem to excrete cholesterol and plant sterols from the enterocyte back into the intestinal lumen [15]. Impairment in function is associated with increased cholesterol and plant sterol absorption. Mutations in the genes encoding $\mathrm{ABC}$ proteins result in early severe atherosclerosis [16]. The NiemannPick disease, type C1-like 1 (NPC1L1) protein and gene have recently been described following the discovery of the drug ezetimibe, which lowers serum cholesterol by reducing cholesterol absorption. Ezetimibe was found to work by inhibiting NPC1L1 [17]. Thus this protein appears to play an important role in regulating intestinal cholesterol absorption [18]. The HMGCoA reductase inhibitors (statins) lower cholesterol and triglycerides. They reduce postprandial chylomicrons in the blood and have been shown in diabetic and non-diabetic patients to make an important contribution to reducing the risk of myocardial infarction $[19,20]$. Inhibition of cholesterol synthesis results in up-regulation of the LDL receptor thus improving clearance not only of the LDL particle but also of the chylomicron and VLDL particles [21,22]. These inhibitors also play a part in regulating chylomicron synthesis and, in preliminary studies, we have shown lower intestinal MTTP expression in both diabetic and non-diabetic subjects taking statin therapy for hypercholesterolaemia [23].

The relationship between MTTP, ABCG5, ABCG8 and NPC1L1 and chylomicron particle composition has not been examined, but is of considerable interest in view of the fact that drugs affecting the above proteins are already on the market or under investigation. The aim of the present study was to examine the relationship between chylomicron composition, MTTP, ABCG5, ABCG8 and NPC1L1 mRNA in type 2 diabetic and non-diabetic patients. A secondary aim was to examine the effect of statin therapy on intestinal expression of the above proteins.

\section{Subjects, materials and methods}

\section{Subjects}

Subjects undergoing routine gastroscopy and biopsy for symptoms suggestive of non-malignant disease (usual symptoms: epigastric or retrosternal discomfort and indigestion) were asked to donate four extra biopsies from the second part of the duodenum (D2) for determination of MTTP, ABCG5 and ABCG8 and NPC1L1 mRNA. Fifteen type 2 diabetic subjects and 17 non-diabetic subjects who were found to have normal duodenal mucosa on histological examination and were not taking lipid-lowering agents were included in the study. Eight of the diabetic patients were being treated by diet alone, 12 were treated with diet and metformin, and six were also taking sulfonylureas. Diabetic patients treated with insulin and subjects with coeliac, thyroid, renal or hepatic disease were excluded. Eleven diabetic patients and four non-diabetic subjects with normal D2 biopsies who were on long-term treatment with varying doses of a statin for hypercholesterolaemia were also examined. All female subjects were postmenopausal. Subjects had no evidence of coeliac, thyroid, renal or hepatic disease. The study was conducted according to the principles outlined in the Declaration of Helsinki. Hospital ethics committee approval was obtained and all subjects gave informed consent.

\section{Intestinal biopsies}

Biopsies were obtained from the second part of the duodenum during gastroscopy. Two biopsy samples were collected in formalin and examined histologically to exclude coeliac, inflammatory bowel disease or malignancy. Three of the non-diabetic subjects had no abnormality on gastroscopy, eight had mild gastritis, six had mild oesophagitis and three mild gastritis and oesophagitis. In the group of four non-diabetic subjects on statin, two had no abnormality, one had mild oesophagitis and one had mild gastritis. Ten of the diabetic patients not on statin had mild oesophagitis and mild gastritis. Two had no abnormality, two had oesophagitis, and one had gastritis only. Of the 11 diabetic patients on statin therapy, four had no abnormality, three had gastritis and oesophagitis, one had gastritis only, and three had oesophagitis. Four separate biopsy samples were collected in RNA later and stored at $-70^{\circ} \mathrm{C}$ for mRNA determination.

\section{Test meal}

Within 1 week of the biopsy collection, patients were invited to attend in the fasting state for a test meal. Seventeen diabetic patients and 12 control subjects agreed to attend. Blood was collected in the fasting state and plasma separated for lipoprotein measurement. Patients were given an $1,100 \mathrm{kcal}$ (fat $55 \%$, carbohydrate $30 \%$ and $15 \%$ protein) test meal. Blood samples were repeated 4 and $6 \mathrm{~h}$ after the meal. After separation of plasma the following preservatives were added to prevent oxidation and degradation of Apo B: phenylalanyl-prolyl-arginyl-chloromethyl ketone $(1 \mathrm{mmol} / \mathrm{l})$, phenylmethylsulfonyl fluoride $(0.1 \mathrm{mmol} / \mathrm{l})$, sodium azide $(0.02 \% \mathrm{w} / \mathrm{v})$, aprotinin $(0.05 \mathrm{TIU})$, EDTA $(0.1 \%)$. 
Lipoprotein analysis

Chylomicrons were isolated by ultracentrifugation as previously described [24]. Blood $\mathrm{HbA}_{1 \mathrm{c}}$ was determined using an enzyme immunoassay kit, containing monoclonal antibody specific for $\mathrm{HbA}_{1 \mathrm{c}}$ (normal value $<5.8 \%$ ) (Novo Nordisk, Cambridge, UK). Total cholesterol and triglyceride content of lipoprotein fractions were measured by an enzymatic colorimetric method using kits from Boehringer Mannheim (Mannheim, Germany) and phospholipids were assayed using a kit from Biomérieux (Marcy l'Etoile, France).

Chylomicron apolipoprotein B48 and B100 determination

Chylomicron Apo B48 and Apo B100 were separated by SDS-polyacrylamide gel electrophoresis using 4 to $15 \%$ gradient gels (Biorad, Herculas, CA, USA) as previously described [24]. Non-delipidated lipoprotein samples (40 $\mu \mathrm{g}$ of protein) were reduced and applied to 4 to $15 \%$ SDSpolyacrylamide gels. Following electrophoresis, gels were stained with Coomassie Brilliant Blue. An Apo B100 standard was prepared from LDL (density $1.025-1.063 \mathrm{~g} /$ $\mathrm{ml}$ ) of a single individual and was stored at $-20^{\circ} \mathrm{C}$ and used throughout the study. Since the chromogenicity of Apo B48 has been shown to be similar to that of Apo B100 [25], we were able to determine the concentration of both Apo B48 and Apo B100 from this standard. Apo B48 and Apo B100 staining was linear within the range $0.1-20 \mu \mathrm{g}$ of protein. The bands were quantified by densitometry (Vilber Lourmat Biotechnology, Marne La Valee, France) and Bio1D v6.32 software (Vilber) for analysis. Density values were assigned to the Apo B100 band of human LDL and a standard curve constructed; the values were recalculated by linear regression. Curves with a correlation coefficient $>0.95$ were accepted. The intra-assay variations were 2.8 and $3.9 \%$ for apoB48 in the chylomicron and VLDL fractions and 4.8 and $6.8 \%$ for Apo B100 in the two fractions. The inter-assay coefficients of variations were 5 and $7 \%$ for Apo B48 and 8 and $8.6 \%$ for Apo B100 in the chylomicron and VLDL fractions, respectively.

\section{Total RNA extraction}

Intestinal biopsy tissue $(10 \mathrm{mg})$ was homogenised in RLT buffer (Qiagen, Crawley, UK) using a Mixer-Mill 300 (Qiagen) and 5-mm stainless steel beads. The RNA content from this homogenised sample was then extracted using the RNeasy Mini Isolation Kit (Qiagen). The sample was also treated with an RNase-free DNase set to eliminate any contaminating DNA. The RNA was then eluted into $50 \mu \mathrm{l}$ RNase-free $\mathrm{H}_{2} \mathrm{O}$, aliquoted, and stored.
RNA quantification

RNA was quantified using an RNA assay kit (Quant-iT Ribogreen; Molecular Probes, Eugene, OR, USA). An RNA standard curve was constructed using dilutions of a supplied, known amount of RNA, and read on a dual band plate reader with an excitation wavelength of $500 \mathrm{~nm}$ and an emission wavelength of $525 \mathrm{~nm}$. Samples were calculated using linear regression from this standard curve.

\section{Reverse transcription}

As part of the two-step real-time RT-PCR, RNA was reverse transcribed to cDNA using TaqMan Reverse Transcription Reagents (Applied Biosystems, Dublin, Ireland). A GeneAmp 2400 PCR System (Applied Biosystems) was used and the conditions were: $10 \mathrm{~min}$ at $25^{\circ} \mathrm{C}, 30 \mathrm{~min}$ at $48^{\circ} \mathrm{C}$ and $5 \mathrm{~min}$ at $95^{\circ} \mathrm{C}$. Eight hundred ng of each sample in $100 \mu \mathrm{l}$ was reverse transcribed to cDNA, with $80 \mathrm{ng}$ of the cDNA to be used in the next step.

\section{Real-time PCR}

In the real-time PCR analysis, we used $10 \mu \mathrm{l}$ of the cDNAcontaining $80 \mathrm{ng}$. The primers and probes for the genes of interest were purchased from Applied Biosystems, using the Assay On Demand system. Thermal cycling conditions and volumes of ingredients are already optimised with this system. The thermal cycling conditions used were: stage 1: $50^{\circ} \mathrm{C}$ for $2 \mathrm{~min}$; stage $2: 95^{\circ} \mathrm{C}$ for $10 \mathrm{~min}$; stage $3: 40$ repetitions of $95^{\circ} \mathrm{C}$ for $15 \mathrm{~s}$ alternating with $60^{\circ} \mathrm{C}$ for $1 \mathrm{~min}$. A sample volume of $25 \mu \mathrm{l}$ was used in each well. Primers and probes were made up in a $20 \times$ stock solution (final concentration $1 \times$ ). A $2 \times$ master mix solution was added to each well at a final concentration of $1 \times$. Into each well, $2 \mu 1$ of the cDNA-containing $80 \mathrm{ng}$ was added separately and a standard deviation on ct value of $<0.3$ was accepted.

Glyceraldehyde-3-phosphate dehydrogenase (GAPDH) was used as the housekeeping gene and all reactions were done as single-plex reactions on a 96-well plate. A TaqMan Universal PCR Master Mix was used (Applied Biosystems) as the mix for the rest of the PCR ingredients. Analysis was run on an ABI-prism 7000 (Applied Biosystems) and the $2^{-\Delta \Delta C T}$ method of relative gene expression was employed. Results were expressed as arbitrary units in comparison with expression of GAPDH.

\section{Statistical analysis}

Statistical analysis was performed using two-tailed Student's $t$-test. Non-parametric tests were used for triglyceride analysis. Correlation coefficients were measured by linear regression analysis. Data are expressed as the mean \pm standard deviation (SD) and mean \pm SEM for graphs. A $p$ value of $<0.05$ was regarded as statistically significant. 
Table 1 Subject characteristics

\begin{tabular}{|c|c|c|c|c|}
\hline & \multicolumn{2}{|c|}{ Diabetic subjects } & \multicolumn{2}{|c|}{ Control subjects } \\
\hline & No statin & Statin & No statin & Statin \\
\hline$N$ & 15 & 11 & 17 & 4 \\
\hline $\mathrm{M} / \mathrm{F}$ & $11 / 4$ & $6 / 5$ & $5 / 12$ & $1 / 3$ \\
\hline Age & $64 \pm 13$ & $59 \pm 9$ & $64 \pm 14$ & $67 \pm 12$ \\
\hline BMI $\left(\mathrm{kg} / \mathrm{m}^{2}\right)$ & $30 \pm 2^{\mathrm{a}}$ & $30 \pm 4^{\mathrm{a}}$ & $24 \pm 3$ & $24 \pm 2$ \\
\hline Plasma cholesterol (mmol/1) & $4.8 \pm 0.5$ & $4.1 \pm 0.9$ & $4.5 \pm 1.0$ & $5.1 \pm 1.0$ \\
\hline Plasma LDL (mmol/1) & $2.4 \pm 0.5$ & $2.1 \pm 0.6$ & $2.5 \pm 0.8$ & $3.6 \pm 1.3$ \\
\hline Plasma HDL (mmol/1) & $1.5 \pm 0.5$ & $1.2 \pm 0.3$ & $1.4 \pm 0.3$ & $1.6 \pm 0.4$ \\
\hline Plasma triglyceride $(\mathrm{mmol} / \mathrm{l})$ & $1.8 \pm 1.4$ & $1.9 \pm 1.2$ & $1.2 \pm 0.7$ & $1-1.9$ \\
\hline Range & $0.7-5.7$ & $1.4-2.1$ & $0.6-2.1$ & $1.0-1.9$ \\
\hline Median & 1.2 & 1.7 & 1.8 & 1.8 \\
\hline $\mathrm{HbA}_{1 \mathrm{c}}(\%)$ & $6.6 \pm 1.1$ & $6.5 \pm 1.3$ & $5.3 \pm 0.3$ & $5.3 \pm 0.2$ \\
\hline
\end{tabular}

Values are mean $\pm \mathrm{SD}$

${ }^{\mathrm{a}} p<0.01$ compared to control subjects

\section{Results}

Subject characteristics

Subject characteristics and plasma lipids are shown in Table 1 . There were 15 type 2 diabetic and 17 non-diabetic control subjects who were not taking statin therapy. Statins were being used to treat hypercholesterolaemia by 11 diabetic and four control subjects. The ages of the four groups were similar but the BMI was significantly higher in the diabetic patients (both statin-treated and non-statintreated) $(p<0.01)$. Plasma lipids were similar among the four groups. The diabetic patients were well controlled with $\mathrm{HbA}_{1 \mathrm{c}}$ of $6.6 \pm 1.1 \%$ (normal value $<5.8 \%$ ) vs $5.3 \pm$ $0.3 \%$ for control subjects. There were more women in the control groups than in the diabetic groups.

Intestinal cholesterol regulatory proteins

MTTP, ABCG5, ABCG8, and NPC1L1 mRNA levels in statin-treated and untreated diabetic and control subjects are shown in Table 2. Among non-statin-treated subjects, diabetic patients had a significant increase in intestinal MTTP mRNA compared to control subjects $(8.76 \pm 5.65 \mathrm{vs}$ $4.87 \pm 3.24$ arbitrary units [AU], $p<0.02$ ) (Fig. 1). $A B C G 5$ and $A B C G 8$ mRNA were both significantly lower in diabetic patients not on statin compared to controls $(0.12 \pm$ 0.07 vs $0.17 \pm 0.08 \mathrm{AU}, p<0.04$ and $0.05 \pm 0.02$ vs $0.1 \pm$ $0.07 \mathrm{AU}, p<0.5$ ) (Fig. 1). There was a close correlation between $A B C G 5$ and $A B C G 8$ mRNA in diabetic and nondiabetic patients $(r<0.84$ and $r=0.83$, respectively, $p<0.001)$. NPC1L1 mRNA was significantly higher in diabetic patients not on statin than in the corresponding control subjects $(2.47 \pm 1.42$ vs $1.39 \pm 1.78$ AU, $p<0.02)$ (Fig. 1).

Among the diabetic patients, 11 were being treated with statins. These patients had significantly less MTTP mRNA than those not on statin $(4.8 \pm 2.47$ vs $8.76 \pm 5.65 \mathrm{AU}$, $p<0.05)$. ABCG5 mRNA was almost double in the diabetic patients on statin, compared with diabetic patients not on statin $(0.21 \pm 0.12$ vs $0.12 \pm 0.07 \mathrm{AU}, p<0.02)$ and for the same groups, there was also a significant increase in $A B C G \&(0.07 \pm 0.03$ vs $0.05 \pm 0.02$ AU, $p<0.05)$. There was a $40 \%$ reduction in NCP1L1 mRNA in diabetic patients on statin, but this did not reach statistical significance $(1.49 \pm$ 0.71 vs $2.47 \pm 1.49 \mathrm{AU}, p<0.06)$. Among control patients, only four were statin-treated. There were no statistically significant differences in the mRNA of the intestinal regulatory proteins studied compared to control subjects not on statin.

Table 2 mRNA levels of MTTP, ABCG5 and $A B C G 8$ and NPC1L1 in diabetic and non-diabetic patients

\begin{tabular}{lllll}
\hline & No statin & & Statin & Control \\
\cline { 2 - 3 } Diabetic & Control & Diabetic & 4 \\
\hline$N$ & 15 & 17 & 11 & $5.05 \pm 1.65$ \\
MTTP & $8.76 \pm 5.65^{\mathrm{b}}$ & $4.87 \pm 3.24$ & $4.80 \pm 2.47^{\mathrm{c}}$ & $0.25 \pm 0.09$ \\
ABCG8 & $0.12 \pm 0.07^{\mathrm{a}}$ & $0.17 \pm 0.08$ & $0.21 \pm 0.12^{\mathrm{d}}$ & $0.15 \pm 0.07$ \\
NPC1L1 & $0.05 \pm 0.02^{\mathrm{a}}$ & $0.10 \pm 0.07$ & $0.07 \pm 0.03^{\mathrm{c}}$ & $1.59 \pm 0.46$ \\
\hline
\end{tabular}

Values are mean $\pm \mathrm{SD}$

${ }^{\mathrm{a}} p<0.05,{ }^{\mathrm{b}} p<0.02$ for difference between diabetic no statin and control no statin

${ }^{\mathrm{c}} p<0.05,{ }^{\mathrm{d}} p<0.02$ for difference between diabetic statin vs no statin 
Fig. 1 Comparison of mRNA expression of MTTP (a) and ABCG5/G8 (b), intestinal proteins regulating cholesterol absorption and chylomicron composition in diabetic $(n=15)$ (black bars) and non-diabetic control patients $(n=17)$ (white bars) not on statin treatment. Mean $\pm \mathrm{SE} * p<0.05$, $* * p<0.02$ compared to control subjects a

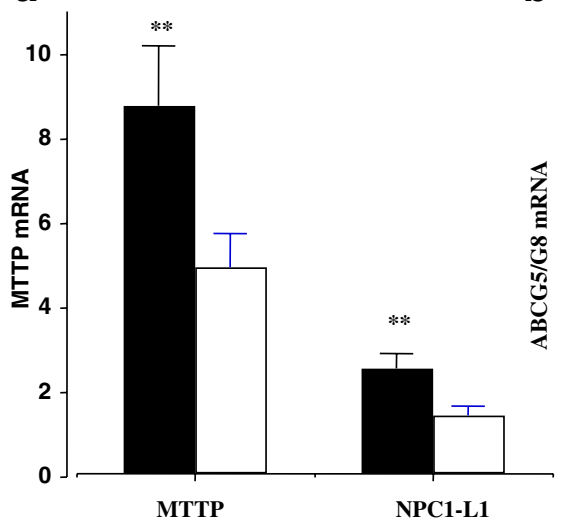

b

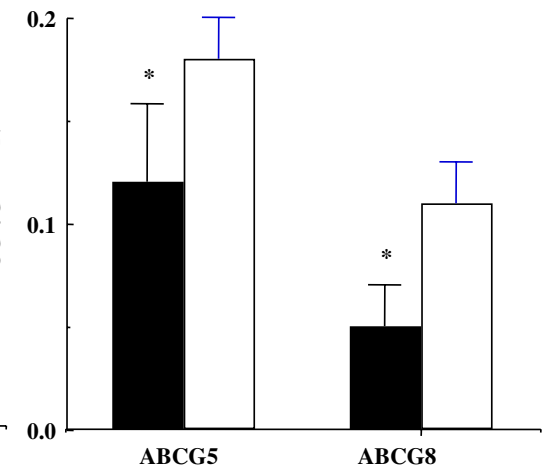

Combining diabetic and non-diabetic subjects who were not on statin treatment, there was a significant positive correlation between $A B C G 5$ and $A B C G 8$ mRNA, as expected (Fig. 2). There was a weak negative correlation between MTTP and ABCG5 mRNA $(r=-0.40, p<0.05)$ (Fig. 2). Analysing the diabetic and control groups separately, there was a negative correlation in the diabetic patients between MTTP and ABCG5 mRNA $(r=-0.53$, $p<0.05)$, whereas in the non-diabetic subjects the correlation did not reach statistical significance. Between MTTP and $A B C G 8$ mRNA there was a weak negative correlation in the combined diabetic and control patients $(r=-0.37$, $p<0.05)$, but in neither the diabetic patients nor control subjects alone did it reach statistical significance. There was no correlation between MTTP and ABCG5 or ABCG8 mRNA in the diabetic patients on statin.

We found a strong positive correlation between MTTP and NPC1L1 mRNA in the combined group of diabetic patients and control patients not on statin $(r=0.78, p<0.001)$ (Fig. 2). In the diabetic patients alone the correlation was $r=0.79, p<0.001$, and in the control subjects $r=0.69$, $p<0.02$. In neither the diabetic nor control patients on statin did we find a correlation between MTTP and NPC1L1 mRNA. There was a negative correlation between $A B C G 5$ and NPC1L1 mRNA $(r=-0.60, p<0.001)$ (Fig. 2) in the combined diabetic and control patients not on statin and a similar correlation between $A B C G 8$ and NPC1L1 mRNA in the combined group $(r=-0.52, p<0.001)$. In the diabetic patients alone, the correlation between $A B C G 5$ and NPCIL1 mRNA was also significant $(r=-0.52$, $p<0.05$ ), but the correlation with $A B C G 8$ mRNA did not reach statistical significance. There was no correlation between $A B C G 5$ or $A B C G 8$ and NPC1L1 mRNA in the control group alone. In the diabetic patients on statin, no correlation was found between either $A B C G 5$ or $A B C G 8$ and NPC1L1 mRNA.
Fig. 2 Correlation of mRNA expression of proteins regulating cholesterol absorption and chylomicron composition in diabetic $(n=15)$ (black squares) and control subjects $(n=17)$ (open circles) not on statin treatment. a ABCG5 vs ABCG8 $(r=0.75, p<0.001)$; b ABCG5 vs MTTP $(r=-0.40, p<0.05)$; c NPC1L1 vs MTTP $(r=0.78$, $p<0.001)$; and d NPC1L1 vs ABCG5 $(r=-0.6, p<0.001)$
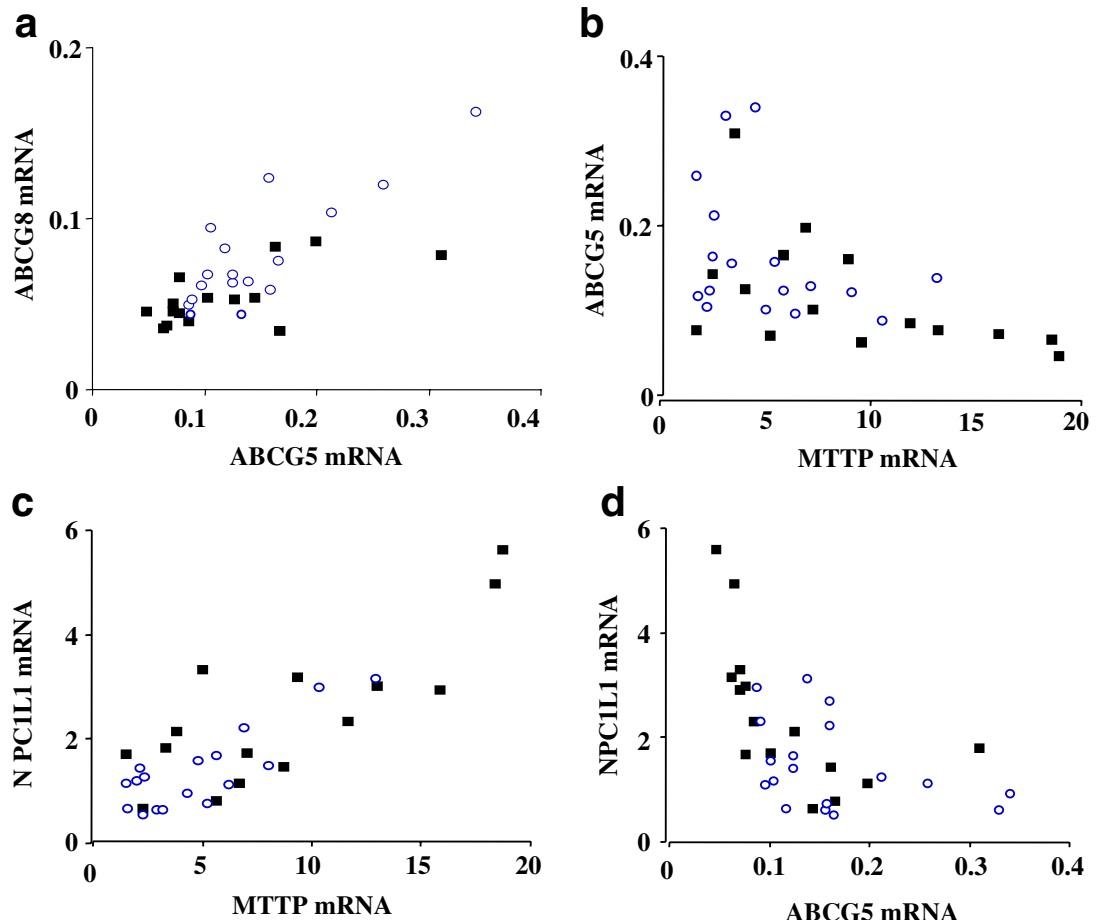

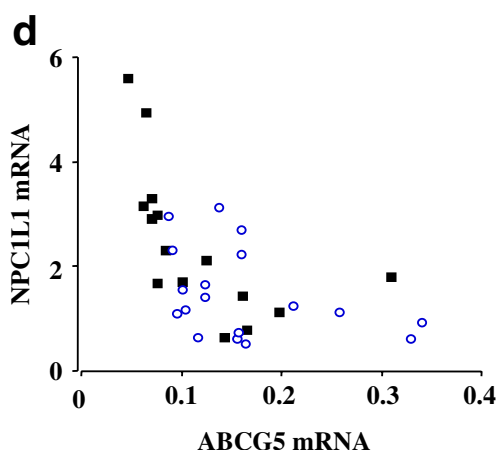


Table 3 Chylomicron composition in diabetic and non-diabetic subjects

\begin{tabular}{|c|c|c|c|c|c|c|}
\hline & \multicolumn{3}{|l|}{ No statin } & \multicolumn{3}{|l|}{ Statin } \\
\hline & Fasting & $4 \mathrm{~h}$ & $6 \mathrm{~h}$ & Fasting & $4 \mathrm{~h}$ & $6 \mathrm{~h}$ \\
\hline Diabetic & $n=8$ & & & $n=10$ & & \\
\hline Apo B100 $(\mu \mathrm{g} / \mathrm{ml}$ plasma $)$ & $1.5 \pm 1.3$ & $7.3 \pm 6.6^{\mathrm{ab}}$ & $5.1 \pm 4.6^{\mathrm{ab}}$ & $1.0 \pm 1.1$ & $5.4 \pm 4.4$ & $4.2 \pm 4.1$ \\
\hline Cholesterol (mg/ml plasma) & $22 \pm 17$ & $99 \pm 53^{\mathrm{b}}$ & $54 \pm 21$ & $25 \pm 5$ & $69 \pm 21$ & $52 \pm 10$ \\
\hline Apo B48 ( $\mu \mathrm{g} / \mathrm{ml}$ plasma $)$ & $1.7 \pm 1.3$ & $6.3 \pm 5.3$ & $9.2 \pm 5.3$ & $1.3 \pm 0.4$ & $10 \pm 7$ & $7.5 \pm 6.5$ \\
\hline Apo B100 ( $\mu \mathrm{g} / \mathrm{ml}$ plasma $)$ & $0.6 \pm 0.6$ & $2.7 \pm 1.7$ & $2.0 \pm 1.1$ & $0.3 \pm 0.2$ & $3.0 \pm 1.7$ & $1.1 \pm 0.6$ \\
\hline Cholesterol (mg/ml plasma) & $21 \pm 15$ & $64 \pm 35$ & $54 \pm 27$ & $29 \pm 8$ & $69 \pm 16$ & $49 \pm 19$ \\
\hline Triglyceride (mg/ml plasma) & $34 \pm 14$ & $140 \pm 124$ & $119 \pm 91$ & $60 \pm 19$ & $196 \pm 90$ & $138 \pm 66$ \\
\hline
\end{tabular}

Values are mean $\pm \mathrm{SD}$

${ }^{\mathrm{a}} p<0.05$ diabetic vs control

${ }^{\mathrm{b}} p<0.05$ diabetic no statin vs statin

\section{Chylomicron composition}

Chylomicron composition for the 17 patients who agreed to a meal is given in Table 3. The diabetic patients not on statin had significantly more Apo B48 in the postprandial chylomicron fraction than control subjects not on statin $(p<0.05)$. We detected a $60 \%$ increase in chylomicron cholesterol at $4 \mathrm{~h}$ (NS), but at $6 \mathrm{~h}$ the levels were similar. There was a significant increase in Apo B100 in the chylomicron fraction in the diabetic patients at both 4 and $6 \mathrm{~h}(p<0.05)$. Chylomicron triglyceride was greater at $4 \mathrm{~h}$ $(p<0.05)$ and was $20 \%$ greater at $6 \mathrm{~h}$ although this did not reach statistical significance. This significance (chylomicron triglyceride at $4 \mathrm{~h}$ ) disappeared when we analysed incremental values from fasting.

Relationship between chylomicron composition and intestinal mRNA

Correlations between chylomicron composition and intestinal mRNA for the combined diabetic and control patients not on statin are shown in Table 4. We found a significant positive correlation in the combined diabetic and nondiabetic patients not on statin treatment at both 4 and $6 \mathrm{~h}$ between MTTP mRNA and postprandial chylomicron cholesterol $(p<0.01)$ and Apo B48 $(p<0.01)$. We also found a positive correlation at 4 and $6 \mathrm{~h}$ between MTTP mRNA and chylomicron Apo B100 $(p<0.01)$ and between MTTP mRNA and chylomicron triglyceride at 4 and $6 \mathrm{~h}$ $(r=0.75, p<0.001)$ (Fig. 3).

There was a significant negative correlation between chylomicron cholesterol and $A B C G 5$ mRNA at 4 and $6 \mathrm{~h}$ $(p<0.05)$ and $A B C G 8 \mathrm{mRNA}$ at $4 \mathrm{~h}(r=-0.46, p<0.05)$, but the correlation at $6 \mathrm{~h}$ did not reach significance. We detected a positive correlation between chylomicron cholesterol and NPC1L1 mRNA at 4 and at $6 \mathrm{~h}(p<0.01)$.

A significant positive correlation was seen between postprandial chylomicron cholesterol and triglyceride at $4 \mathrm{~h}(r=0.72, p<0.001)$ and $6 \mathrm{~h}(r=0.74, p<0.001)$ (Fig. 3).

The only significant correlations in the statin-treated combined group were between MTTP mRNA and triglyceride at both 4 and $6 \mathrm{~h}(r=0.71$ and $r=0.64, p<0.01)$, and between MTTP mRNA and cholesterol at $6 \mathrm{~h}(r=0.68$, $p<0.01)$ but not at $4 \mathrm{~h}$. There was also a positive correlation between chylomicron cholesterol and NPC1L1 mRNA at $6 \mathrm{~h}(p<0.01)$.

\section{Discussion}

This cross-sectional study demonstrates increased intestinal MTTP mRNA in diabetic subjects and a positive correlation between postprandial chylomicron composition

Table 4 Correlations between chylomicrons and intestinal mRNA in the combined group of diabetic and control patients not on statin treatment

\begin{tabular}{|c|c|c|c|c|c|c|c|c|c|}
\hline \multirow{2}{*}{$\begin{array}{l}n=17 \\
\text { Chylomicrons }\end{array}$} & \multirow[b]{2}{*}{ Time } & \multicolumn{2}{|c|}{ MTTP } & \multicolumn{2}{|c|}{ ABCG5 } & \multicolumn{2}{|c|}{ ABCG8 } & \multicolumn{2}{|c|}{ NPC1L1 } \\
\hline & & $r$ & $p<$ & $r$ & $p<$ & $r$ & $p<$ & $r$ & $p<$ \\
\hline \multirow[t]{2}{*}{ Apo B48 } & $4 \mathrm{~h}$ & 0.68 & 0.001 & -0.58 & 0.01 & -0.35 & ns & 0.86 & 0.001 \\
\hline & $6 \mathrm{~h}$ & 0.65 & 0.01 & -0.50 & 0.50 & -0.23 & ns & 0.63 & 0.01 \\
\hline \multirow[t]{2}{*}{ Apo B100 } & $4 \mathrm{~h}$ & 0.79 & 0.001 & -0.56 & 0.01 & -0.28 & ns & 0.88 & 0.001 \\
\hline & $6 \mathrm{~h}$ & 0.63 & 0.01 & -0.49 & 0.05 & -0.23 & ns & 0.68 & 0.001 \\
\hline \multirow[t]{2}{*}{ Cholesterol } & $4 \mathrm{~h}$ & 0.82 & 0.001 & -0.46 & 0.05 & -0.35 & $\mathrm{~ns}$ & 0.68 & 0.001 \\
\hline & $6 \mathrm{~h}$ & 0.77 & 0.01 & -0.62 & 0.01 & -0.43 & 0.05 & 0.70 & 0.001 \\
\hline
\end{tabular}


Fig. 3 Relationship between MTTP mRNA and postprandial (4 h) chylomicron composition in diabetic ( $n=8$ black squares) and control $(n=9$, open circles) patients. a MTTP vs chylomicron Apo B48 $(r=0.83$, $p<0.001)$; b MTTP vs chylomicron Apo B100 $(r=0.79$, $p<0.001)$; c MTTP vs chylomicron triglyceride $(r=0.62$, $p<0.01$ ); and d MTTP vs chylomicron cholesterol $(r=0.83, p<0.001)$

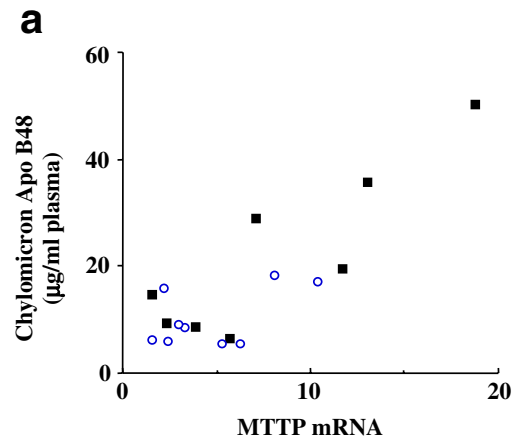

b

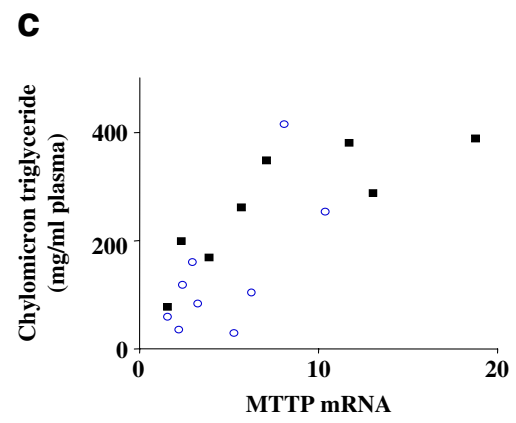

and MTTP mRNA. These results are similar to a previous study on a separate group of subjects using the RNase protection assay to measure MTTP mRNA [23]. We are unaware of any previous reports of intestinal $A B C G 5$ and $A B C G 8$ and NPC1L1 mRNA expression in human subjects. In the present study there was a close correlation between $A B C G 5$ and $A B C G 8$ mRNA in both diabetic and control subjects (Fig. 3), which was expected since these proteins are known to work in tandem to expel cholesterol from the enterocyte [18]. Diabetic patients had significantly lower $A B C G 5$ and $A B C G 8$ mRNA expression, suggesting they have an impairment in the re-excretion of cholesterol from the enterocyte back into the lumen. The negative correlation between MTTP mRNA and both $A B C G 5$ and $A B C G 8$ mRNA suggests that the increase in available cholesterol may stimulate MTTP expression leading to a significant increase in the number of chylomicron particles. This is supported by the negative correlation between both postprandial chylomicron cholesterol and Apo B48, and $A B C G 5$ and $A B C G 8$ mRNA. NPC1L1 is responsible for transporting cholesterol across the membrane [18]. It is uncertain whether the protein also regulates the absorption of cholesterol synthesised in the intestine. NPC1L1 mRNA was significantly higher in the intestine of diabetic patients than in that of control subjects (Fig. 1), suggesting that diabetic patients have increased absorption of cholesterol. Animal and human studies have not demonstrated an increase in dietary cholesterol absorption in type 2 diabetes [26, 27], but have shown an increase in intestinal cholesterol synthesis. We suggest that the increase in NPC1L1 results in increased absorption of biliary cholesterol and possibly of newly synthesised cholesterol in the intestine.

This study demonstrates a significant positive relationship between MTTP mRNA and NPC1L1 expression in the intestine. This again suggests that MTTP, which has a positive sterol response element [28], is upregulated in response to the increased cholesterol absorption. The negative correlation between NPC1L1 mRNA and ABCG5 and $A B C G 8$ mRNA suggests a co-ordinated mechanism to regulate cholesterol homeostasis. Thus in times of cholesterol need, absorption is increased through upregulation of NPC1L1 and downregulation of ABCG5 and ABCG8. In type 2 diabetes it would appear that the increase in NPC1L1 and decrease in ABCG5 and ABCG8 leads to the increase in chylomicron cholesterol. The relationship of the above mRNA levels to chylomicron composition which we observed in this study, and which we have previously reported for MTTP mRNA [29, 30], suggests that the mRNA level does affect the activity, although in this study we were unable to measure protein or activity directly. The promoter region of the gene encoding MTTP has a negative insulin response element [31] and we have previously speculated that this may influence the raised levels of MTTP mRNA which we find in diabetes. It is interesting to see that polymorphisms in the Q604E allele of the $A B C G 5$ gene in men were associated with insulin resistance [32]. In streptozotocin-induced diabetes in rats it has been shown that intestinal mRNA expression of $A B C G 5$ and $A B C G 8$ and ABCG5 protein content were reduced as was $A B C G 5$ and $A B C G 8$ expression in the liver [33].

This study demonstrates that cholesterol can be lowered by inhibition of HMGCoA reductase, which reduces cholesterol synthesis and downregulates MTTP mRNA, again demonstrating the importance of cholesterol in regulating MTTP. We had expected that inhibition of cholesterol synthesis would increase NPC1L1 mRNA, since NPC1L1 deficiency results in upregulation of HMGCoA reductase. It has recently been shown that NPC1L1 null mice had increased HMGCoA synthase 
expression [18]. In acute experiments, inhibition of NPC1L1 by ezetimibe does not affect acute intestinal or hepatic cholesterol synthesis in rats [34], but we are unaware of any other studies on the relationship between HMGCoA reductase inhibition and NPC1L1 mRNA. Our study showed a $40 \%$ reduction in NCP1L1 mRNA in diabetic patients treated with statin, but this decrease did not reach statistical significance, although it might do with larger numbers of subjects. We had so few patients on statin in the control group that our study does not permit definite conclusions about the effect of statin in non-diabetic patients. In non-diabetic patients, Matthan et al. [35] have shown an increase in cholesterol absorption in patients with coronary artery disease and low HDL who were taking simvastatin with niacin. The general conclusion, however, appears to be that statins increase cholesterol absorption [36-39]. Our results demonstrate an increase rather than decrease in $A B C G 5$ and $A B C G 8$ mRNA in statin-treated patients and suggest that perhaps the increase in sterol absorption upregulates the $\mathrm{ABC}$ pathway in an attempt to limit the increased sterol absorption load. It may be, as has been suggested, that the net result of statin therapy, with regard to the balance of decreased synthesis and altered cholesterol absorption, may depend on the dose of statin and whether the patients are high or low cholesterol absorbers. It is possible that the method of measuring cholesterol absorption by measuring the ratio of plant sterol to cholesterol is no longer reliable when cholesterol synthesis is inhibited by drugs such as statins since, particularly in patients who are low absorbers of sterols, there would be very major changes in the ratio of plant sterol to cholesterol, even if there was no change in cholesterol absorption [40].

We found good evidence to support the role of cholesterol in stimulating MTTP mRNA. The reduction in MTTP mRNA in patients on statin therapy suggests a major role of synthesised rather than absorbed cholesterol in regulating MTTP. However, we also found a strong correlation between MTTP mRNA and chylomicron triglyceride. This confirms the interdependence of cholesterol and triglyceride in the postprandial phase. We therefore looked to see whether there was a correlation between cholesterol and triglyceride in the postprandial chylomicron fractions after the high-fat meal and found significant positive correlations in both $4 \mathrm{~h}$ and $6 \mathrm{~h}$ chylomicron fractions. MTTP and ABCG5/G8 play an important role in cholesterol homeostasis in the liver. There is no information on the relationship between intestinal and hepatic mRNA levels in diabetic or nondiabetic subjects. The positive correlation between MTTP mRNA and Apo B100 in the chylomicron fraction and the negative correlation between ABCG5 and chylomicron Apo B100 suggest that intestinal levels may reflect hepatic mRNA levels. The strong correlation between NPC1L1 mRNA and Apo B100 may just reflect the interdependence between Apo B48 and Apo B100 in uptake by the B/E receptor, which accepts Apo B48 chylomicron particles in preference to Apo B100 particles.
Postprandial lipoproteins are now believed to play an important role in atherosclerosis [41]. In diabetes, a condition with accelerated atherosclerosis, LDL cholesterol is frequently normal although compositional differences have been described [42]. The postprandial lipoproteins are known to influence LDL composition [43], but are also atherogenic in their own right [5], and it is probably of considerable importance that there is a specific Apo B48 receptor on the macrophage [44]. The present study confirms previously described alterations in chylomicron composition in type 2 diabetes and explains for the first time the mechanisms that result in the production of an abnormal chylomicron particle. There is considerable evidence to suggest that the chylomicron is atherogenic and can deliver significant amounts of cholesterol to the atherosclerotic plaque. Alteration of intestinal proteins regulating cholesterol absorption and chylomicron formation in type 2 diabetes may result in a less atherogenic postprandial chylomicron particle leading to a reduction in atherosclerosis.

Acknowledgements The authors wish to thank The Diabetes Federation of Ireland, The Meath Hospital Foundation and The Health Research Board for financial support of the work.

\section{References}

1. Iovine C, Vaccaro O, Gentile A et al (2004) Post-prandial triglyceride profile in a population-based sample of Type 2 diabetic patients. Diabetologia 47:19-22

2. Geluk CA, Halkes CJ, De Jaegere PP, Plokker TW, Cabezas MC (2004) Daytime triglyceridemia in normocholesterolemic patients with premature atherosclerosis and in their first-degree relatives. Metabolism 53:49-53

3. Curtin A, Deegan P, Owens D, Collins P, Johnson A, Tomkin GH (1994) Alterations in apolipoprotein B48 in the postprandial state. Diabetologia 37:1259-1262

4. Madigan C, Ryan M, Owens D, Collins P, Tomkin GH (2005) Postprandial lipoprotein particles are deficient in apo E in Type 2 diabetes: a cause of postprandial hyperlipidaemia? Ir J Med Sci 174:8-21

5. Karpe F, Steiner G, Uffelman K, Olivecrona T, Hamsten A (1994) Postprandial lipoproteins and progression of coronary atherosclerosis. Atherosclerosis 106:83-97

6. Mero N, Malmstrom R, Steiner G, Taskinen MR, Syvanne M (2000) Postprandial metabolism of apolipoprotein B-48- and B-100 containing particles in type 2 diabetes mellitus: relations to angiographically verified severity of coronary artery disease. Atherosclerosis 150:167-177

7. Phillips C, Madigan C, Owens D, Collins P, Tomkin GH (2002) Defective chylomicron synthesis as a cause of delayed particle clearance in diabetes? Int J Exp Diabetes Res 3:171-178

8. Dane-Stewart CA, Watts GF, Barrett PH et al (2003) Chylomicron remnant metabolism studied with a new breath test in postmenopausal women with and without type 2 diabetes mellitus. Clin Endocrinol (Oxf) 58:415-420

9. O’Meara N, Devery R, Owens D, Collins P, Johnson A, Tomkin GH (1991) Serum lipoproteins and cholesterol metabolism in two hypercholesterolaemic rabbit models. Diabetologia 3:139-143

10. O'Meara N, Devery R, Owens D, Collins P, Johnson A, Tomkin GH (1990) Cholesterol metabolism in the alloxaninduced diabetic rabbit. Diabetes 39:626-633 
11. Phillips C, Murugasu G, Owens D, Collins P, Johnson A, Tomkin GH (2000) Improved metabolic control reduces the number of postprandial apolipoprotein B48-containing particles in Type 2 diabetes. Atherosclerosis 148:283-291

12. Hussain MH (2000) A proposed model for assembly of chylomicrons. Atherosclerosis 148:1-15

13. Hussain MM, Fatma S, Pan X, Iqbal J (2005) Intestinal lipoprotein assembly. Curr Opin Lipidol 16:281-285

14. Feingold KR, Wilson DE, Wood LC, Kwong LK, Moser AH, Grunfeld C (1994) Diabetes increases hepatic hydroxymethyl glutaryl coenzyme A reductase protein and mRNA levels in the small intestine. Metabolism 43:450-454

15. Lee MH, Lu K, Graf GA et al (2001) Identification of a gene, ABCG5, important in the regulation of dietary cholesterol absorption. Nat Genet 27:79-83

16. Berge KE, Tian H, Graf GA et al (2000) Accumulation of dietary cholesterol in sitosterolemia caused by mutations in adjacent ABC transporters. Science 290:1771-1775

17. Altmann SW, Davis HR Jr, Zhu IJ et al (2004) Niemann-Pick C1 Like 1 protein is critical for intestinal cholesterol absorption. Science 303:1201-1204

18. Davis HR, Zhu IJ, Hoos LM et al (2004) Niemann-Pick C1 Like 1 (NPC1L1) is the intestinal phytosterol and cholesterol transporter and a key modulator of whole-body cholesterol homeostasis. J Biol Chem 279:33586-33592

19. Schaefer EJ, McNamara JR, Tayler T et al (2004) Comparisons of effects of statins (atorvastatin, fluvastatin, lovastatin, pravastatin, and simvastatin) on fasting and postprandial lipoproteins in patients with coronary heart disease versus control subjects. Am J Cardiol 93:31-39

20. Pyorala K, Pedersen TR, Kjekshus J, Fraergeman O, Olsson AG, Thorgeirsson G, The Scandinavian Simvastatin Survival Study (4S) Group (1997) Cholesterol-lowering with simvastatin improves prognosis of diabetic patients with heart disease. Diabetes Care 20:614-620

21. Dane-Stewart CA, Watts GF, Pal S et al (2003) Effect of atorvastatin on apolipoprotein B48 metabolism and low-density lipoprotein receptor activity in normolipidemic patients with coronary artery disease. Metabolism 52:279-286

22. van Wijk JP, Buirma R, van Tol A et al (2005) Effects of increasing doses of simvastatin on fasting lipoprotein subfractions, and the effect of high-dose simvastatin on postprandial chylomicron remnant clearance in normotriglyceridemic patients with premature coronary sclerosis. Atherosclerosis 178:147-155

23. Phillips C, Mullan K, Owens D, Tomkin GH (2005) Intestinal microsomal triglyceride transfer protein in type 2 diabetic and non-diabetic subjects: the relationship to triglyceride-rich postprandial lipoprotein composition. Atherosclerosis (DOI: 10.1016/j.atherosclerosis.2005.08.020)

24. Phillips C, Murugasu G, Owens D, Collins P, Johnson A, Tomkin GH (2000) Improved metabolic control reduces the number of postprandial apolipoprotein B48-containing particles in Type 2 diabetes. Atherosclerosis 148:283-291

25. Karpe F, Hamsten A (1994) Determination of apolipoproteins B48 and B100 in triglyceride-rich lipoproteins by analytical SDS-PAGE. J Lipid Res 35:1311-1317

26. Gleeson A, Owens D, Collins P, Johnson A, Tomkin GH (2000) The relationship between cholesterol absorption and intestinal cholesterol synthesis in the diabetic rat model. Internat J Exp Diab Res 1:203-210

27. Gylling H, Miettinen TA (1997) Cholesterol absorption, synthesis and LDL metabolism in NIDDM. Diabetes Care 20:90-95
28. Hagan DL, Keinzle B, Jamil H, Hariharan N (1994) Transcriptional regulation of human and hamster microsomal triglyceride transfer protein genes. Cell type-specific expression and response to metabolic regulators. J Biol Chem 269:28737-28744

29. Phillips C, Anderton K, Bennett A et al (2002) Intestinal rather than hepatic microsomal triglyceride transfer protein as a cause of postprandial dyslipidaemia in diabetes. Metabolism 51: 847-852

30. Phillips C, Owens D, Collins P, Tomkin GH (2002) Altered expression of microsomal triglyceride transfer protein and increased lymph chylomicron production in the insulin resistant zucker obese fa/fa rat. Atherosclerosis 160:355-360

31. Linn MC, Gordon D, Wetterau JR (1995) Microsomal triglyceride transfer protein (MTP) regulation in HepG2 cells: insulin negatively regulates MTP gene expression. J Lipid Res 36:1073-1108

32. Gylling H, Hallikainen M, Pihlajamaki J et al (2004) Polymorphisms in the ABCG5 and ABCG8 genes associate with cholesterol absorption and insulin sensitivity. J Lipid Res 45:1660-1665

33. Bloks VW, Bakker-Van Waarde WM, Verkade HJ et al (2004) Down-regulation of hepatic and intestinal Abcg5 and Abcg8 expression associated with altered sterol fluxes in rats with streptozotocin-induced diabetes. Diabetologia 47:104-112

34. van Heek M, Farley C, Compton DS, Hoos LM, Smith-Torhan A, Davis HR (2003) Ezetimibe potently inhibits cholesterol absorption but does not affect acute hepatic or intestinal cholesterol synthesis in rats. Br J Pharmacol 138:1459-1464

35. Matthan NR, Giovanni A, Schaefer EJ, Brown BG, Lichtenstein AH (2003) Impact of simvastatin, niacin, and/or antioxidants on cholesterol metabolism in CAD patients with low HDL. J Lipid Res 44:800-806

36. Ntanios FY, Jones PJ, Frohlich JJ (1999) Effect of 3-hydroxy-3methylglutaryl coenzyme A reductase inhibitor on sterol absorption in hypercholesterolemic subjects. Metabolism 48:68-73

37. Gylling H, Miettinen TA (2002) Baseline intestinal absorption and synthesis of cholesterol regulate its response to hypolipidaemic treatments in coronary patients. Atherosclerosis 160: $477-481$

38. Miettinen TA, Gylling H (2003) Synthesis and absorption markers of cholesterol in serum and lipoproteins during a large dose of statin treatment. Eur J Clin Invest 33:976-982

39. Watts GF, Chan DC, Barrett PH, O'Neill FH, Thompson GR (2003) Effect of a statin on hepatic apolipoprotein B-100 secretion and plasma campesterol levels in the metabolic syndrome. Int J Obes Relat Metab Disord 27:862-865

40. Mathan NR, Lichtenstein AH (2004) Approaches to measuring cholesterol absorption in humans. Atherosclerosis 174:197-205

41. Tanaka A (2004) Postprandial hyperlipidemia and atherosclerosis. J Atheroscler Thromb 11:322-329

42. Schaeffer PG, Teerlink T, Heine RJ (2005) Clinical significance of the physiochemical properties of LDL in type 2 diabetes. Diabetologia 48:808-816

43. Lahdenpera S, Syvanne M, Kahri J, Taskinen MR (1996) Regulation of low-density lipoprotein particle size distribution in NIDDM and coronary disease: importance of serum triglycerides. Diabetologia 39:453-461

44. Gianturco SH, Ramprasad MP, Song R, Li R, Brown ML, Bradley WA (1998) Apolipoprotein B48 or its apolipoprotein B100 equivalent mediates the binding of triglyceride-rich lipoproteins to their unique human monocyte-macrophage receptor. Arterioscler Thromb Vasc Biol 18:968-976 